Tohoku J. Exp. Med., 2010, 220, 127-138

\title{
Fractionation of Mature Eosinophils in GATA-Reporter Transgenic Mice
}

\author{
Kibom Kim, ${ }^{1}$ Norio Suzuki, ${ }^{1}$ Kinuko Ohneda, ${ }^{2}$ Naoko Minegishi ${ }^{3,4}$ and \\ Masayuki Yamamoto ${ }^{4}$

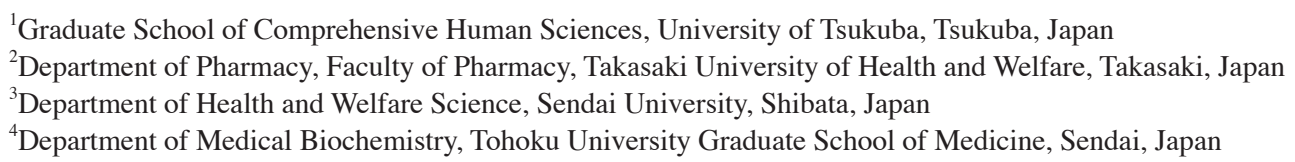

Eosinophils contribute to the pathophysiology of allergic and infectious diseases, albeit their molecular functions remain unknown. Mature eosinophils are identified by their unique morphology and staining characteristics. However, it is difficult to fractionate living eosinophils by flow cytometry because these granulocytes express multiple cell surface markers that are shared by other cells of hematopoietic or non-hematopoietic origin. In this study, we describe a flow cytometry-based method to enumerate and fractionate eosinophils by developmental stages. To fractionate these cell types, we used transgenic mouse lines that express fluorescent proteins under control of the Gata1 gene hematopoietic regulatory region (Gata1-HRD), which is exclusively active in Gata1-expressing hematopoietic cells, including eosinophils. As expected, mature eosinophils were highly enriched in the fluorescent reporter-expressing subfraction of bone marrow myeloid cells that were negatively selected by using multiple antibodies against B220, CD4, CD8, Ter119, c-Kit and CD71. Cytochemical analyses of flow-sorted cells identified the cells in this fraction as eosinophils harboring eosinophilic granules. Additionally, expression of eosinophil-specific genes, for instance eosinophil enzymes and the IL-5 receptor alpha gene, were specifically detected in this fraction. The expression of these eosinophil-specific genes increased as the cells differentiated. This method for enrichment of bone marrow eosinophils is applicable to fractionation of eosinophils and bronchoalveolar lavage fluid from transgenic mice with atopic asthma. Thus, both pathological and developmental stages of eosinophils are efficiently fractionated by this flow cytometry-based method using Gata1-HRD transgenic reporter mice. This study, therefore, proposes a useful means to study the experimental allergic and inflammatory systems.

Keywords: Eosinophils/GATA1/GATA2/transgenic mice/flow cytometry

Tohoku J. Exp. Med., 2010, 220 (2), 127-138. ㅇ 2010 Tohoku University Medical Press

Eosinophils are multifunctional granulocytes implicated in diverse immune responses, which include parasitic infections and allergic disease. Eosinophils normally constitute only $1-3 \%$ of peripheral blood cells, but upon diverse stimuli, are increased in number and recruited to sites of inflammation (Humbles et al. 2004; Lee et al. 2004; Rothenberg and Hogan 2006). Eosinophils secrete a variety of granule-associated pro-inflammatory cytotoxic proteins, including major basic protein (MBP) and eosinophil peroxidase (EPX), which contribute to airway damage and alterations in airway structure (reviewed in Rothenberg and Hogan 2006).

Allergic disease of the respiratory tract is characterized by the increased infiltration of eosinophils into the associated tissues (Rothenberg and Hogan 2006). Detection and quantification of eosinophils in fluids, such as bronchoalveolar lavage fluid (BALF) or lung tissue are standard procedures in murine models of allergic disease and viral infection. For example, when mice are challenged with aerosolized chicken ovalbumin (OVA), the eosinophil population increases in an interleukin (IL)-5-dependent manner in the bone marrow, peripheral blood and in the BALF (Foster et al. 1996; Kopf et al. 1996). Detection of eosinophils has primarily been based on morphologic criteria, i.e., granulocytes with prominent eosinophil-specific basic granules (Shen et al. 2003; Ishizaki et al. 2006; Stevens et al. 2007). This morphologic identification approach has several disadvantages, including variability in staining procedures, uniformity of inflammatory cell distribution, and reliance on the subjective interpretation of cell morphology in

Received November 9, 2009; revision accepted for publication December 10, 2009. doi:10.1620/tjem.220.127

Correspondence: Masayuki Yamamoto, M.D., Ph.D., Department of Medical Biochemistry, Tohoku University Graduate School of Medicine, 2-1 Seiryo-cho, Aoba-ku, Sendai 980-8575, Japan.

e-mail: masiyamamoto@m.tains.tohoku.ac.jp 
the quantitation of infiltrating cells.

To investigate molecular events in disease influenced by the eosinophil population, fractionation of living eosinophils is necessary. To date, specific types of monoclonal antibodies combined with strict forward/side scatter gating are used in flow cytometry-based methods to fractionate the cells (Hansel et al. 1991; Du et al. 2002; Iwasaki et al. 2005; Ishizaki et al. 2006; Munoz and Leff 2006; Stevens et al. 2007; Fukushima et al. 2009; Mori et al. 2009; Shen et al. 2009). However, expression of multiple cell surface markers (e.g. CD16, Gr1, Mac1, etc) that are shared by other cells of hematopoietic origin and are normally present in inflammatory infiltrates, hampers the easy detection of eosinophils using flow cytometry (Hansel et al. 1991; Gounni et al. 2000; Stevens et al. 2007; Fukushima et al. 2009). To analyze the physiology and pathology of eosinophils, cytokine-induced differentiation systems of hematopoietic progenitor cells or cell lines are exploited (Clutterbuck and Sanderson 1988; Clutterbuck et al. 1989; Caldenhoven et al. 1998; Yamaguchi et al. 1999; Querfurth et al. 2000; Dyer et al. 2008; Fukushima et al. 2009; Qiu et al. 2009). However, it is possible that cytokine-induced eosinophils are crucially different from eosinophils in vivo.

GATA1 and GATA2 are in members of a family of GATA-type zinc finger transcription factors (Yamamoto et al. 1990; Ferreira et al. 2005; Shimizu et al. 2008). Targeting knockout of these genes resulted in embryonic lethality due to impaired hematopoiesis (Tsai et al. 1994; Fujiwara et al. 1996; Takahashi et al. 1997). In adult hematopoiesis, GATA2 is expressed in hematopoietic stem/ progenitor cells and in immature erythroid/megakaryocyte lineage cells, while GATA1 is expressed in a later stage of erythroid/megakaryocytic cells (Weiss and Orkin 1995; Takahashi et al. 1998; Yang et al. 2000; Minegishi et al. 2003; Kobayashi-Osaki et al. 2005; Suzuki et al. 2006; Muntean et al. 2007). GATA1 expression in dendritic cells has also been reported (Gutierrez et al. 2007). Both GATA1 and GATA2 are expressed in eosinophils, mast cells, and basophils (Zon et al. 1993; Harigae et al. 1998; Weiss and Orkin 1995; Yamaguchi et al. 1998; Hirasawa et al. 2002; Iwasaki et al. 2005, 2006; Takemoto et al. 2008). Maturation of mast cells and eosinophils, as well as megakaryocyte/erythroid cells, is impaired in GATA1deificeint mice (Harigae et al. 1998; Takahashi et al. 1998; Hirasawa et al. 2002; Yu et al. 2002).

Common granulocyte/monocyte progenitors produce single-lineage committed progenitors for eosinophils, mast cells and basophils (Iwasaki et al. 2005; Arinobu et al. 2009). Several transcription factors, including GATA1, GATA2, PU.1 and the C/EBP family factors regulate eosinophil development from myeloid progenitor cells (Du et al. 2002; McNagny and Graf 2002; Iwasaki et al. 2005, 2006). In the $\triangle$ dblGATA mouse, which lacks double GATA motifs in the Gatal gene promoter, GATA1 expression in eosinophils is markedly decreased and eosinophils are depleted (Yu et al. 2002). However, in another report, the hematopoietic enhancer is not important while the first intron of the Gatal gene is important for GATA1 expression in eosinophils (Guyot et al. 2004). On the other hand, the balance between GATA2 and $\mathrm{C} / \mathrm{EBP} \alpha$ expression regulates the cell-fate decision of progenitor cells (Iwasaki et al. 2006). RNA silencing and overexpression experiments demonstrate that GATA2 and $\mathrm{C} / \mathrm{EBP} \alpha$, but not GATA1, drive eosinophil-specific gene expression (Fukushima et al. 2009; Qiu et al. 2009). These data suggest that GATA1 and GATA2 might regulate common but separate pathways of eosinophil development, and that expression of these genes might be used as a tool for isolating eosinophils.

In this study we aimed to characterize the eosinophil differentiation pathway by utilizing reporter mice that express green or red fluorescent protein (GFP and RFP, respectively) under the regulation of the Gatal and Gata2 genes. To monitor the expression of Gatal and Gata2 genes simultaneously, we also generated a compound reporter mouse line (G1-Red:G2-GFP mouse line) that expresses red and green fluorescent proteins under the control of the Gatal and Gata2 regulatory domains, respectively. The G1-Red:G2-GFP mice were subjected to intranasal OVA challenge to monitor the reactivity of eosinophils during various stages of development. These results indicated that G1-Red:G2-GFP transgenic mice might be a useful tool for studies of eosinophils in allergic response and infectious diseases.

Methods
Mice
To construct the G1-Red transgene, Gatal-HRD (Onodera et al. 1997; Suzuki et al. 2003) was ligated to DsRed2 cDNA (Clontech, Mountain View, CA). We established four lines of G1-Red transgenic mice and the highest DsRed-expressing line was mainly used in this study. For screening G1-Red transgenic mice, tail DNA was extracted and the DsRed 2 transgene was detected by polymerase chain reaction (PCR) using a pair of primers, Red-S (5'-ACGGCTCCAAGG TGTACGTG-3 ${ }^{\prime}$ ) and Red-AS ( $5^{\prime}$-CTCCCAGCCCATGGTCTTC- $3^{\prime}$ ). Both G1-GFP (Gatal-HRD-GFP) mice and G2-GFP (Gata2 EIS-KI) mice have been described previously (Suzuki et al. 2003, 2006). To generate G1-Red:G2-GFP mice, G1-Red mice and G2-GFP mice were mated. All mice were treated according to the regulations of the Standards for Human Care and Use of Laboratory Animals of the University of Tsukuba. Mice were analyzed from 9 to 16 weeks of age.

Flow cytometry and cell sorting

Cell sorting and marker analysis were performed using FACS Vantage SE and Cell Quest software (Becton Dickinson, San Jose, CA). Mononuclear cell suspensions from bone marrow, peripheral blood, and bronchoalveolar lavage fluid (BALF) of the transgenic mice were prepared and incubated with biotinylated monoclonal antibodies recognizing Ter119, B220, CD4, CD8 (for the lymphoid and erythroid markers, LyE), and CD71. Cells negative for both markers ( $\mathrm{LyE}^{-} / \mathrm{CD} 71^{-}$cells) were enriched by magnetic negative selection using streptavidin-conjugated magnetic beads (BioMag; Polysciences, Warrington, PA), followed by staining with allophycocyanin (APC)- 
conjugated anti-c-Kit antibodies, streptavidin-conjugated phycoerythrin (PE)-Texas Red and propidium iodide (PI; Sigma, St Louis, MO, USA). For G1-GFP and G2-GFP mice, enriched $\mathrm{LyE}^{-}$cells were stained with PE-conjugated anti-CD71 antibody, APC-conjugated anti-c-Kit antibody, streptavidin-conjugated PE-Texas Red, and PI. For G1-Red mice, enriched $\mathrm{LyE}^{-}$cells were stained with fluorescein isothiocyanate (FITC)-conjugated anti-CD71 antibody, APCconjugated anti-c-Kit antibody, streptavidin-conjugated PE-Texas Red, and PI. All antibodies and streptavidin-conjugated fluorochromes were purchased from BD Pharmingen (San Diego, CA).

Cytochemistry

Flow-sorted cells were subjected to cytospin and analyzed for Wright-Giemsa (MUTO, Tokyo) and EoProbe (BioFX, Owings Mills, MD) staining. Cells positive for EoProbe were observed under the fluorescent microscope (Leica Microsystems, Wetzlar, Germany) after exposure to $561-\mathrm{nm}$ wavelength excitation for 10 seconds to quenching auto fluorescence.

\section{Colony assay}

Sorted cells were cultured in $1 \mathrm{ml}$ of $0.8 \%$ methylcellulose medium containing $30 \%$ fetal bovine serum (FBS). For detection of eosinophil colony-forming units, medium was supplemented with 100 $\mathrm{ng} / \mathrm{ml}$ of IL-5 (R\&D Systems, Minneapolis, MN) and $100 \mathrm{ng} / \mathrm{ml}$ of stem cell factor (SCF) (PeproTech, Rocky Hill, NJ). Single-cell derived colonies were counted after 9 days of culturing, and photographs of some of growing colonies were taken everyday during the 14-day cultivation by a multi-color and fixed point observation system of a BZ-8000 fluorescent microscope (Keyence, Osaka, Japan).

\section{Quantitative RT-PCR}

Total RNA was extracted from 5,000 flow-sorted cells using an
RNeasy kit (Qiagen, Basel, Switzerland) and reverse-transcribed by a Sensicript RT Kit (Qiagen) with random hexamers. Quantitative PCR samples were analyzed by either SYBR Green or fluorescent probe systems (Eurogentec, Seraing, Belgium) with the gene-specific primers listed in Table 1 using an ABI PRISM 7700 Sequence Detector (Applied Biosystems, Foster City, CA). Glyceraldehyde phosphate dehydrogenase (GAPDH) mRNA levels were used as internal controls.

\section{Allergen sensitization and challenge}

Age-matched (9- to 16-week old) G1-Red:G2-GFP mice, which were back-crossed with Balb/c mice more than 6 times, were sensitized and challenged with chicken ovalbumin (OVA) as described previously (Sakai et al. 1999) with some modifications. Briefly, on days 0 and 7 , mice were intraperitoneally injected with $100 \mu \mathrm{g}$ of OVA (crude grade IV; Sigma, St. Louis, MO), which was emulsified in 1 $\mathrm{mg}$ of aluminum hydroxide/magnesium hydroxide (Pierce, Rockford, IL). The sensitized mice were intranasally challenged with $15 \mu \mathrm{g}$ of OVA in $30 \mu 1$ of saline on days 14,15 , and 16 . On day 18 , peripheral blood cells were collected through the retro-orbital plexus after anesthesia, and the BALF-derived cells were obtained from the tracheae by lavaging the lungs 3 times with $0.5 \mathrm{ml}$ of ice-cold PBS containing $2 \%$ FBS.

\section{Results}

Isolation of eosinophils from bone marrow using Gatalreporter expression

We first attempted to isolate eosinophils from the bone marrow of G1-GFP transgenic mice, which express GFP under the control of Gatal-HRD (Suzuki et al. 2003). After magnetic-bead depletion of Ter119-, B220-, CD4- or CD8-

Table 1. DNA primers and probe sets for quantitative RT-PCR.

\begin{tabular}{|c|c|c|c|}
\hline & Gene & 5’ Primer sequence & 3’ Primer sequence \\
\hline \multirow[t]{2}{*}{1} & Gatal & 5'-CAGAACCGGCCTCTCATCC & 5'-TAGTGCATTGGGTGCCTGC \\
\hline & & VIC-labeled probe, 5'-CCCAAGAAGCGAATGATTGTC & CAGCAAA \\
\hline \multirow[t]{2}{*}{2} & Gata2 & 5'-GAATGGACAGAACCGGCC & 5'-AGGTGGTGGTTGTCGTCTGA \\
\hline & & VIC- labeled probe, $5^{\prime}$-AAGCGGAGGCTGTCTGCTGCC & CAAG \\
\hline \multirow[t]{2}{*}{3} & GAPDH & 5'-GAAGGTGAAGGTCGGAGTC & 5'-GAAGATGGTGATGGGATTTC \\
\hline & & JOE- labeled probe, $5^{\prime}$-CAAGCTTCCCGTTCTCAGCC & \\
\hline \multirow[t]{2}{*}{4} & $M B P$ & 5'-CCCCTGGAGGACACTCTTCT & 5'-GGAGCGTCTGCTCTTCATCT \\
\hline & & FAM- labeled probe, $5^{\prime}$-GGACCAGA & \\
\hline \multirow[t]{2}{*}{5} & $E P X$ & $5^{\prime}$-TCACTTGACCGAGTGTCACC & 5'-CTCCTGACTAACCGCTCTGC \\
\hline & & FAM- labeled probe, $5^{\prime}$-CTGCTTCC & \\
\hline \multirow[t]{2}{*}{6} & $C / E B P \alpha$ & 5'-GACCAGAAAGCTGAGTTGTGAG & 5'-CCACAAAGCCCAGAAACCTA \\
\hline & & FAM- labeled probe, $5^{\prime}$-CTTCCAGC & \\
\hline \multirow{2}{*}{7} & $C / E B P \beta$ & 5'-TGATGCAATCCGGATCAA & 5'-ACACGTGTGTTGCGTAGTCC \\
\hline & & FAM- labeled probe, $5^{\prime}$-TGGCTGAG & \\
\hline 8 & CD34 & 5'-GGGTAGCTCTCTGCCTGATG & 5'-TCCGTGGTAGCAGAAGTCAA \\
\hline 9 & Fogl & 5'-CATGGCTAGTCCCTGGAGTG & 5'-CCAGGATAGGCCCTCAGTG \\
\hline 10 & $C / E B P \varepsilon$ & 5'-TCCCCTGCAGTACCAAGTG & 5'-GTGCCTTGAGAAGGGGACT \\
\hline 11 & $I L-5 R \alpha$ & 5'-GGTCCCGGTATGCAGTTCTA & 5'-GGAAGACCCTGGTTAGATCCTT \\
\hline
\end{tabular}

Each mRNA expression level was examined by quantitative RT-PCR analysis using the listed DNA primers. PCR was performed with a fluorescent probe system (1-7) or a SYBR Green system (8-11) using an ABI7300 sequential detector. 

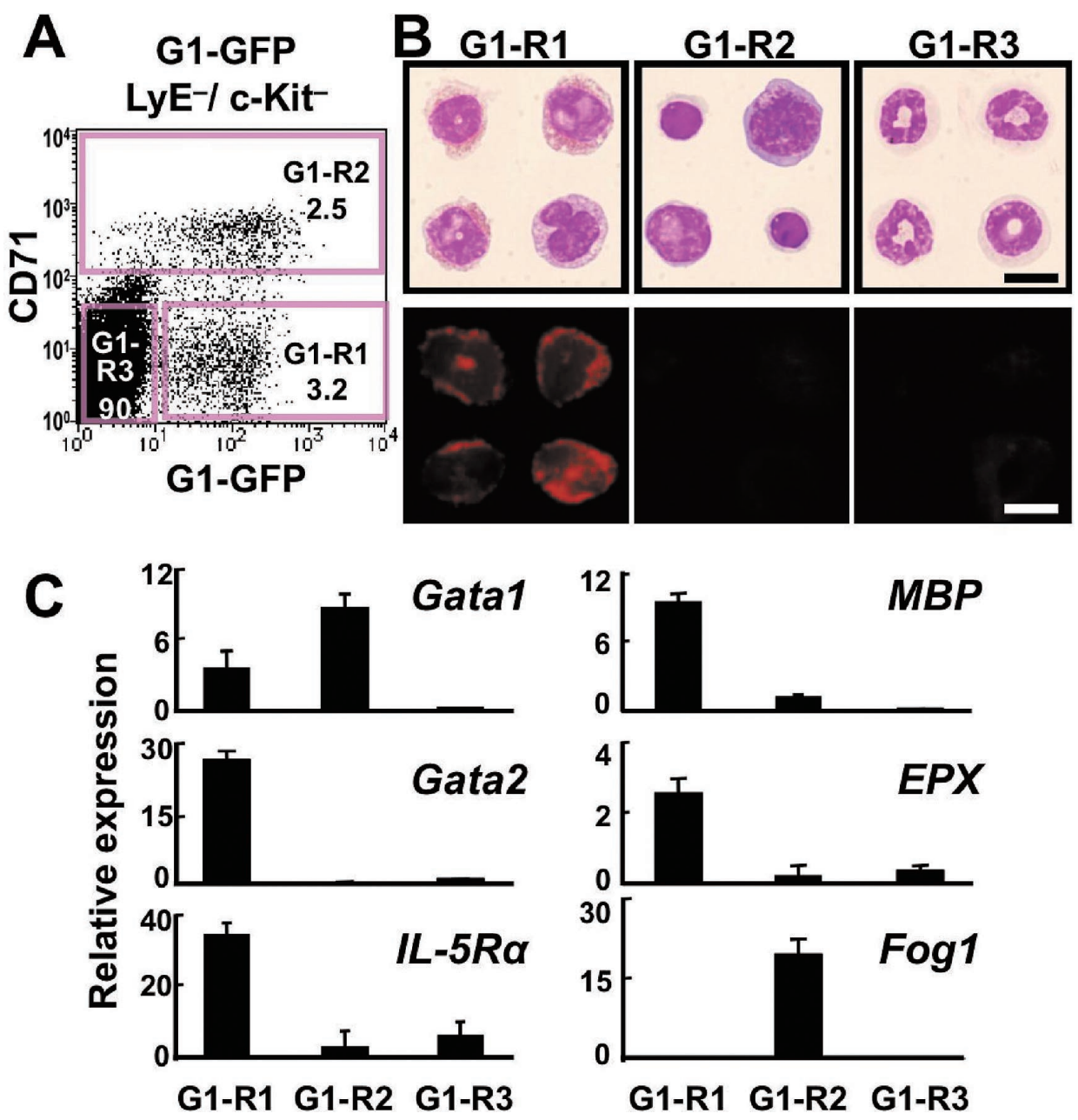

Fig. 1. Isolation of eosinophils from bone marrow using Gatal-reporter expression.

(A) Flow cytometry for CD71 and GFP expression of $\mathrm{LyE}^{-} / \mathrm{c}-\mathrm{Kit}^{-}$hematopoietic mononuclear cells from the bone marrow of G1-GFP mice. The percentage in each region (G1-R1, G1-R2 and G1-R3) is shown. (B) Wright-Giemsa (top) and EoProbe (bottom) staining of cells in each region. Scale bars represent $10 \mu \mathrm{m}$. (C) Relative mRNA expression levels of the indicated genes in cells from each region were measured by quantitative RT-PCR. The results were normalized to the expression level of GAPDH mRNA and are shown with the standard deviation from 3 or more independent experiments.

expressing cells $\left(\mathrm{LyE}^{-}\right)$, we isolated $\mathrm{LyE}^{-} / \mathrm{c}-\mathrm{Kit}^{-} / \mathrm{CD} 71^{-} / \mathrm{G} 1-$ $\mathrm{GFP}^{+}$cells (G1-R1 fraction; Fig. 1A). Morphological examination by Wright-Giemsa staining demonstrated that the cells in the G1-R1 fraction contained segmented nuclei and distinct large pink (eosinophilic) granules in the cytoplasm (Fig. 1B, upper left). Cells in each fraction were analyzed with EoProbe staining, which stains the eosinophilspecific basic cytoplasm by red fluorescence. Using this technique, red fluorescence was markedly observed in the G1-R1 fraction of isolated cells (Fig. 1B). In the G1-R1 fraction, strong red fluorescence was observed in over $80 \%$ of the cells, and modest or weak fluorescence was detected in the remaining $20 \%$ of cells (Fig. 1B). The data suggest that eosinophils are highly enriched in G1-R1 fraction of the G1-GFP mouse bone marrow. Cells with basophil-like morphology were not readily observed in G1-R1 fraction.

We compared mRNA expression in G1-R1 $\left(\mathrm{LyE}^{-} / \mathrm{c}-\right.$ $\left.\mathrm{Kit}^{-} / \mathrm{CD} 71^{-} / \mathrm{G} 1-\mathrm{GFP}^{+}\right), \mathrm{G} 1-\mathrm{R} 2\left(\mathrm{LyE}^{-} / \mathrm{c}-\mathrm{Kit}^{-} / \mathrm{CD} 71^{+}\right)$, and
G1-R3 (LyE ${ }^{-} / \mathrm{c}-\mathrm{Kit}^{-} / \mathrm{CD} 71^{-} / \mathrm{G} 1-\mathrm{GFP}^{-}$) fractions by quantitative RT-PCR (Fig. 1C). Gatal mRNA was expressed in the G1-R1 fraction, albeit lower then in the G1-R2 fraction. High levels of Gata2, IL-5R $\alpha, M B P$ and EPX mRNA expression were identified specifically in G1-R1 fraction, while Fog 1 mRNA was not readily detected in the G1-R1 fraction. In contrast, Gatal and Fogl mRNAs was abundantly expressed in the G1-R2 fraction, which contains immature erythroid cells (Suzuki et al. 2003). FOG-1 (Friend of GATA-1) is one of the well-studied cofactors of GATA1 (Chang et al. 2002) that are expressed in erythroid/ megakaryocyte lineage cells, but not in eosinophils (Querfurth et al. 2000). These results thus demonstrate that G1-GFP is a useful marker for eosinophil isolation from the bone marrow, and that cells in the eosinophil lineage are highly enriched in the G1-R1 fraction. It is interesting to note that, in agreement with previous reports on eosinophils (Querfurth et al. 2000; McNagny and Graf 2002; Qiu et al. 
2009), both Gatal and Gata2 mRNA was expressed in the G1-R1 eosinophilic fraction.

\section{Simultaneous expression of Gatal and Gata2 reporters in eosinophil colonies}

Because Gata2 mRNA was detected in the G1-R1 fraction, we attempted to isolate eosinophils using reporter expression under the regulatory influence of the Gata2 gene. For this purpose, we utilized G2-GFP mice in which the GFP gene is knocked into the Gata2 gene IS exon (Suzuki et al. 2006). GFP expression in G2-GFP mice has been previously shown to recapitulate GATA2 expression in hematopoietic stem/progenitor cells (Suzuki et al. 2006). We also generated a transgenic mouse line that expresses red fluorescent protein under the regulatory influence of Gatal-HRD (G1-Red mouse line). To monitor Gatal- and Gata2- reporter expression in individual mice, we crossed G1-Red mice with G2-GFP mice to obtain G1-Red:G2-GFP mice.

In eosinophil colony forming assays, we found that $\mathrm{LyE}^{-} / \mathrm{c}-\mathrm{Kit} / \mathrm{CD} 71^{-}$cells from the bone marrow formed no eosinophil colonies, indicating that these cells were further differentiated from the colony-forming progenitor stage. In contrast, eosinophil colonies were formed from $\mathrm{LyE}^{-} / \mathrm{c}-\mathrm{Kit}^{+} /$ CD71- mononuclear cells (data not shown). During growth of the eosinophil colonies from $\mathrm{LyE}^{-} / \mathrm{c}-\mathrm{Kit}^{+} / \mathrm{CD} 71^{-}$cells, each single colony simultaneously began to emit both green and red fluorescence, and some of cells in the colonies co-expressed G1-Red and G2-GFP (Fig. 2A). This observation suggests that both GATA1 and GATA2 are simultaneously expressed in proliferating eosinophils.

\section{The Gata 2 reporter is expressed by a small portion of eosinophil lineage cells}

We identified GFP-positive cells from the bone marrow of G2-GFP mice as a small population $(\mathrm{G} 2-\mathrm{R} 1,0.7 \%$; Fig. 2B) in the $\mathrm{LyE}^{-} / \mathrm{c}-\mathrm{Kit}^{-} / \mathrm{CD} 71^{-}$fraction. The G2-R1 fraction contained cells with pink granules in the cytoplasm (with Wright-Giemsa staining) and with EoProbe red fluorescence (Fig. 2C); however, the number of granules was less and intensity of the fluorescence was weaker in the majority of cells in this fraction than cells in the G1-R1 fraction. Eosinophil-specific genes, $I L-5 R a, M B P, E P X$ and $C / E B P \varepsilon$ were expressed in the G2-R1 fraction, although the expression level was low compared with the G1-R1 fraction (Fig. 2D). It was previously reported that the $C / E B P \alpha$ gene is mainly expressed in immature hematopoietic cells, including the eosinophil progenitors (Iwasaki et al. 2006). We found that $C / E B P \alpha$ was expressed higher in the G2-R1 fraction than in the G1-R1 fraction, suggesting that G2-R1 fraction also contained immature hematopoietic cells.

Taken together, these results indicate that the G2-R1 fraction, to some extent, contains cells belonging to eosinophil lineage. This population $\left(0.7 \%\right.$ of $\mathrm{LyE}^{-} / \mathrm{c}-\mathrm{Kit}^{-} / \mathrm{CD} 71^{-}$ fraction; Fig. 2B) is smaller than that of the eosinophilic fraction defined by G1-GFP expression (G1-R1, 3.2\%; Fig.
1A). Furthermore, the data suggest that a large number of Gata1-expressing eosinophils might not express Gata2-GFP fluorescence.

Gata1 - and Gata2- reporter expression in bone marrow cells

To analyze the relationship between GATA1 and GATA2 expression in the eosinophil lineage, we conducted flow cytometry analysis of G1-Red:G2-GFP mouse bone marrow. The $\mathrm{LyE}^{-} / \mathrm{c}-\mathrm{Kit}^{-} / \mathrm{CD} 71^{-}$fraction was divided into four subpopulations by expression of G1-Red and G2-GFP (Fig. 3A; G1G2-R1 to G1G2-R4 fractions). In agreement with the G1-R1 analysis, we found cells that possessed segmented nuclei and abundant basic granules (stained pink by Wright-Giemsa stain) in the G1G2-R3 fraction (G1-Red ${ }^{+} /$ G2-GFP'; Fig. 3B, left panels). These cells were densely stained with EoProbe (Fig. 3B, right panels), indicating that this G1G2-R3 fraction contains eosinophils, as is the case for the G1-R1 fraction. Cells in the G1G2-R2 fraction (G1$\mathrm{Red}^{+} / \mathrm{G} 2-\mathrm{GFP}^{+}$) also possessed pink granules by WrightGiemsa stain and showed fluorescence with EoProbe (Fig. 3B). In contrast, cells in G1G2-R1 fraction (G1-Red /G2$\mathrm{GFP}^{+}$) contain a much lower number of eosinophilic granules, if any, and were stained only weakly with EoProbe (Fig. 3B). More than $80 \%$ of cells were positive for EoProbe in every eosinophilic fraction (G1G2-R1, -R2 and -R3), though the fluorescent intensities of the staining were different among these 3 fractions. Cells with the brightest staining were observed in the G1G2-R3 fraction, while most of cells were dully stained in the G1G2-R1 fraction (Fig. 3B). These results seem to reflect a stepwise maturation of eosinophils, which progresses from the G1G2-R1 to G1G2-R3 fractions through G1G2-R2 fraction. However, further experiments are required for solid confirmation of this observation.

Consistent with the results from RT-PCR experiments in G1-GFP mice (see Fig. 1), expression of eosinophil-specific genes were detected in G1-Red ${ }^{+}$fractions (G1G2-R2 and G1G2-R3; Fig. 3C). Expression of the $C / E B P \alpha$ and $\mathrm{CD} 34$ genes were high in $\mathrm{G} 2-\mathrm{GFP}^{+}$fractions $(\mathrm{G} 1 \mathrm{G} 2-\mathrm{R} 1$ and G1G2-R2; Fig. 3C), suggesting that G2-GFP expression might identify immature hematopoietic cells. Since detected expression levels of Gatal mRNA in G1-Red-negative cells (G1G2-R1 fraction) was similar to the G1G2-R3 fraction positive for G1-Red expression (Fig. 3C), Gatal-HRD reporter transgene expression might not fully represent endogenous Gatal gene expression, as we mentioned in our previous report (Suzuki et al. 2003). These results thus reinforce that there are at least three flow-sorted fractions corresponding to relatively differentiated eosinophil stages after the colony-forming stages. These three eosinophil fractions are detectable by using the expression patterns of Gatal and Gata2 genes. 


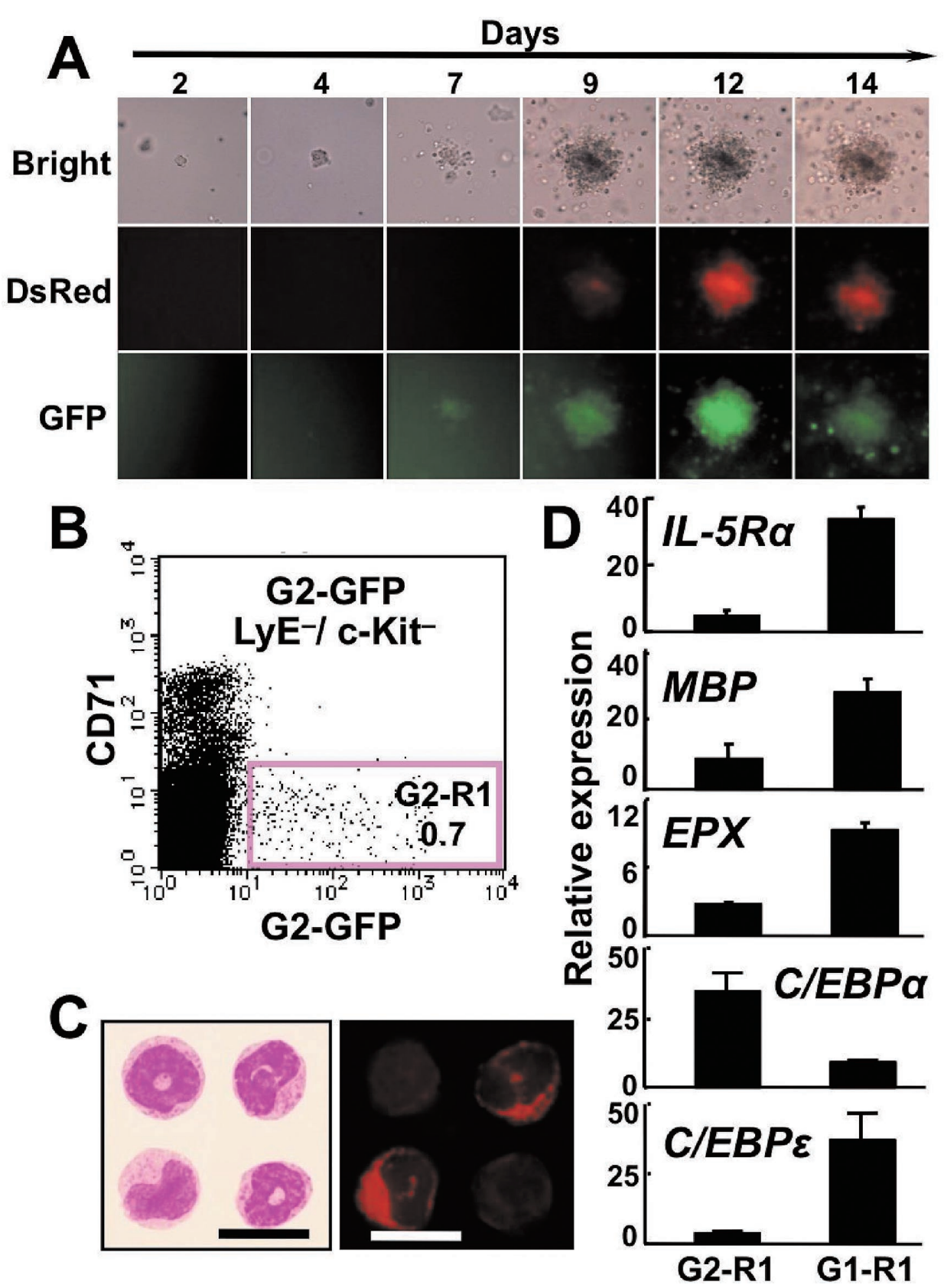

Fig. 2. Isolation of eosinophils from bone marrow using Gata2-reporter expression.

(A) $\mathrm{LyE}^{-} / \mathrm{c}-\mathrm{Kit}^{+} / \mathrm{CD} 71^{-}$cells from the bone marrow of G1-Red:G2-GFP mice were cultured with IL-5 and SCF in semisolid medium and time-lapse images of a growing single colony were taken by bright field (top), DsRed (G1-Red, middle) and GFP (G2-GFP, bottom) on the indicated days. (B) Flow cytometry for CD71 and GFP expression of $\mathrm{LyE}^{-} /$ $\mathrm{c}-\mathrm{Kit}^{-}$hematopoietic mononuclear cells from the bone marrow of G2-GFP mice demonstrates that $0.7 \%$ of $\mathrm{LyE}^{-} / \mathrm{c}-\mathrm{Kit}^{-}$ cells express G2-GFP (G2-R1 region, purple box). (C) Wright-Giemsa (left) and EoProbe (right) staining of cells in G2-R1 region. Scale bar is $10 \mu \mathrm{m}$. (D) Relative mRNA expression levels of indicated genes in G2-R1 cells from each region were measured by quantitative RT-PCR and compared with G1-R1 eosinophilic cells (see Fig. 1). The results were normalized to the level of GAPDH mRNA and are shown with the standard deviation from 3 or more independent experiments. blood

Expression of Gata1 and Gata2 reporters in peripheral

We next analyzed fluorescent expression of G1-Red and G2-GFP in peripheral blood eosinophils. As is the case with bone marrow cells, the $\mathrm{LyE}^{-} / \mathrm{c}-\mathrm{Kit}^{-} / \mathrm{CD} 71^{-}$cell fraction in peripheral blood from G1-Red:G2-GFP mice was divided into four subfractions by expression of G1-Red and G2-GFP
(G1G2-R1 to G1G2-R4 fractions; Fig. 4A). Cells isolated from each fraction were stained by Wright-Giemsa and EoProbe (Fig. 4B) and the results demonstrated that the percentage of eosinophils in the G1G2-R3 fraction was low $(20 \%$ to $40 \%)$. This is unlike the bone marrow G1G2-R3 fraction, in which more than $80 \%$ of cells belong to the eosinophil lineage. The majority of cells in any of the 
A

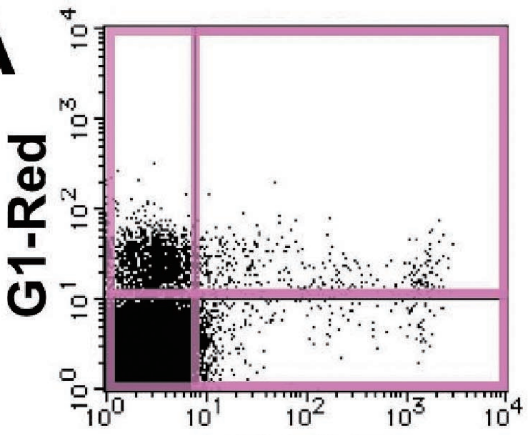

G2-GFP
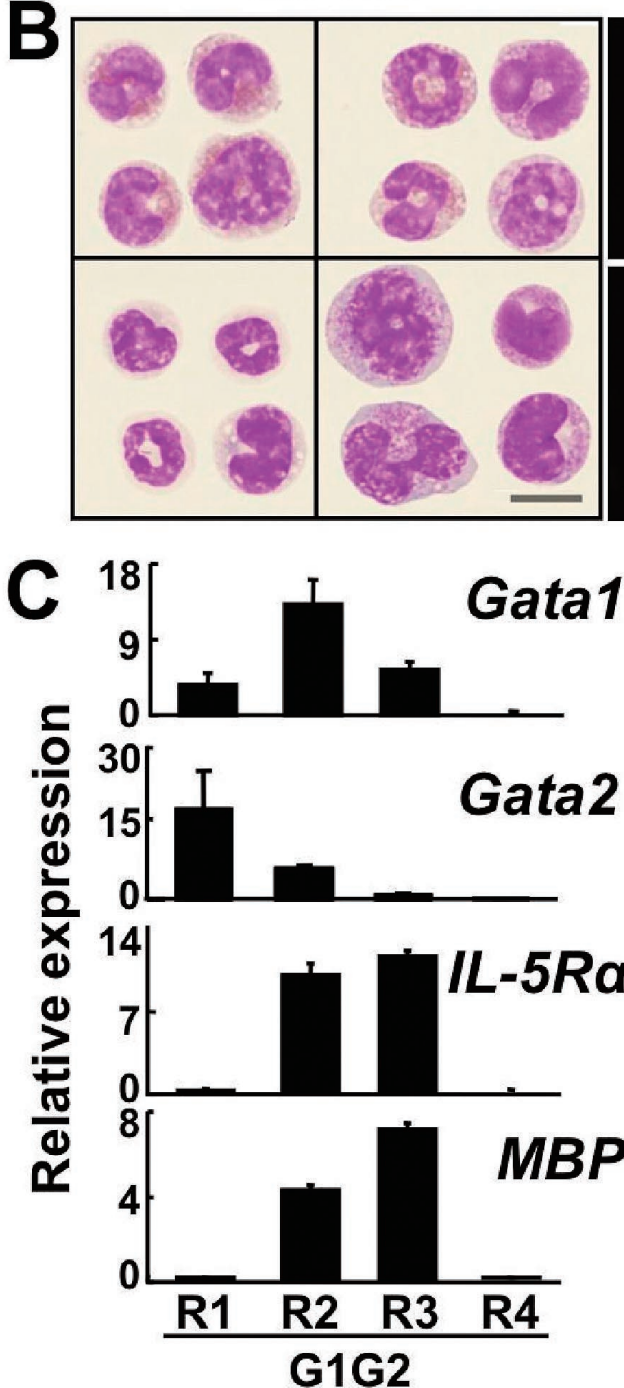
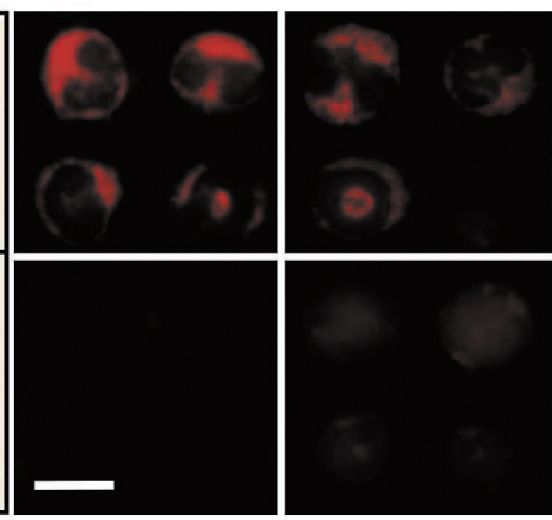

G1-Red:G2-GFP ${\text { LyE } / \mathrm{C}-\mathrm{Kit}^{-} / \mathrm{CD71}}^{-}$

\begin{tabular}{|c|c|}
\hline $\begin{array}{c}\text { G1G2-R3 } \\
(4.6 \%)\end{array}$ & $\begin{array}{c}\text { G1G2-R2 } \\
(0.9 \%)\end{array}$ \\
\hline G1G2-R4 & G1G2-R1 \\
$(94.1 \%)$ & $(0.4 \%)$ \\
\hline
\end{tabular}
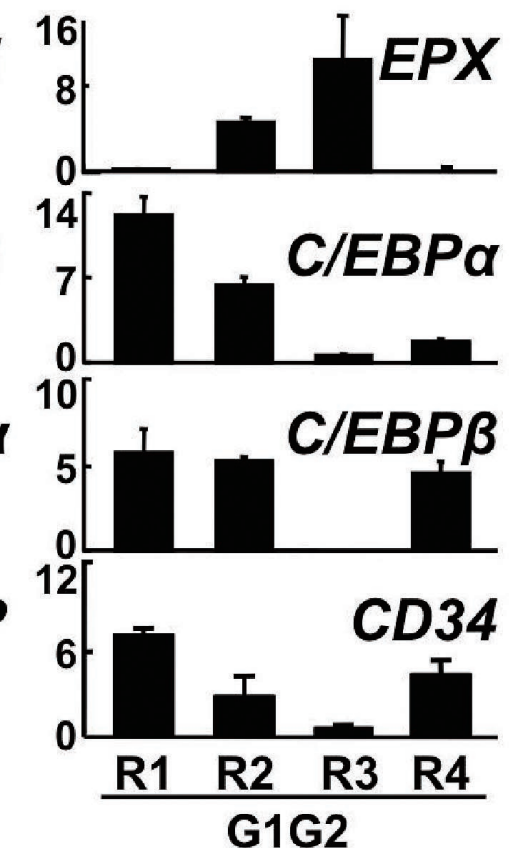

Fig. 3. Isolation of eosinophils from bone marrow by combinatorial monitoring of Gata1- and Gata2-reporter expression. (A) $\mathrm{LyE}^{-} / \mathrm{c}-\mathrm{Kit}^{-} / \mathrm{CD} 71^{-}$hematopoietic mononuclear cells from the G1-Red:G2-GFP mouse bone marrow were divided into four sub-fractions with DsRed2 (G1-Red) and GFP (G2-GFP) expression. The percentage of cells in each quadrangle of the data from flow cytometry (left) is represented in the right boxes with the name and position of each region. (B) Wright-Giemsa (left panels) and EoProbe (right panels) staining of cells in each region. Cells in G1G2-R1 (lower right), -R2 (upper right), -R3 (upper left) and -R4 (lower left) are shown. The position of each panel is represented in A. Scale bars are $10 \mu \mathrm{m}$. (C) Relative mRNA expression levels of indicated genes in cells from each region were measured by quantitative RT-PCR. The results were normalized to the level of GAPDH mRNA and are shown with the standard deviation from 3 or more independent experiments. 

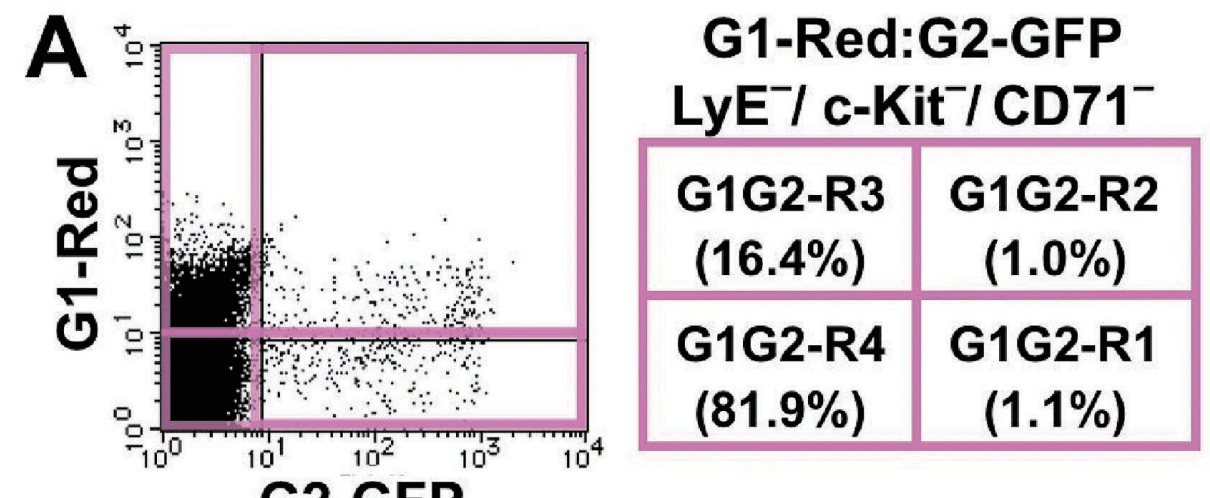

B

G2-GFP
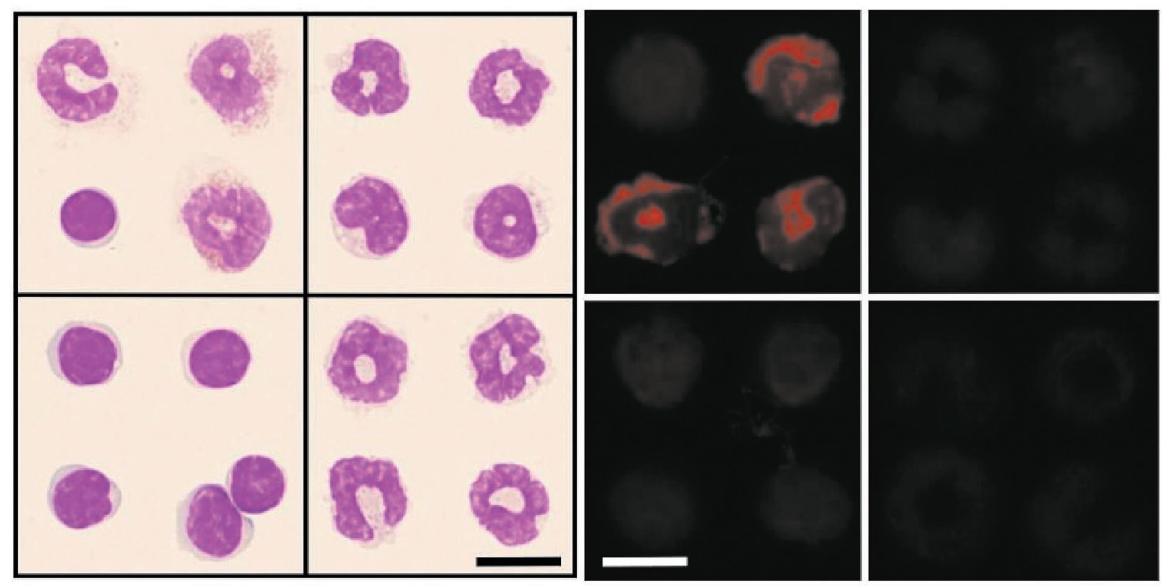

Fig. 4. Isolation of eosinophils from peripheral blood of G1-Red:G2-GFP mice.

(A) Flow cytometry for DsRed2 (G1-Red) and GFP (G2-GFP) expression of $\mathrm{LyE}^{-} / \mathrm{c}-\mathrm{Kit}^{-} / \mathrm{CD}^{-} 1^{-}$hematopoietic mononuclear cells from peripheral blood of G1-Red:G2-GFP mice. The percentage of cells in each quadrangle (left) is represented in the right boxes as well as in Fig. 3A. (B) Flow-sorted cells in each region were subjected to Wright-Giemsa (left) and EoProbe (right) staining. The position of each panel is represented and each cell fraction is indicated by boxes in $\mathrm{A}$ (same with Fig. 3B). Scale bars represent $10 \mu \mathrm{m}$.

G1G2-R1, G1G2-R2 and G1G2-R3 fractions of peripheral blood were lymphocytes or neutrophils (Fig. 4B), which might be contamination during flow-cytometry sorting due to the low number of cells in these fractions. These results indicate that fully differentiated eosinophils (G1G2-R3 fraction) tend to migrate from the bone marrow to peripheral blood.

\section{Eosinophils increased in number in response to allergen} challenge

Eosinophils in G1-Red:G2-GFP mice were analyzed using an experimental model of acute asthma (Sakai et al. 1999) to study how eosinophils react to allergen challenge. In the bone marrow, the populations of the G1G2-R2 and G1G2-R3 eosinophils significantly increased as a result of OVA challenge (Fig. 5A and B). Morphological analyses showed that the percentages of eosinophils in these two fractions were not altered by OVA challenge (more than $80 \%$ ). Additionally, the G1G2-R3 fraction in peripheral blood was increased under the acute asthma condition (Fig.
5A and B). Although we could not efficiently enrich eosinophils from peripheral blood, the increase in cell population in the peripheral blood G1G2-R3 fraction most likely reflects an increase in the number of eosinophils, because the rate of eosinophil concentration in the G1G2-R3 fraction was elevated 2 to 3 fold (approximately 60\%) after OVA challenge (data not shown). While there were few cells in the G1G2-R3 (G1-Red $\left.{ }^{+} / \mathrm{G} 2-\mathrm{GFP}^{-}\right)$fraction of BALF under normal conditions (Fig. 5A and B) (Stevens et al. 2007), the apparent cell population was increased in the G1G2-R3 fraction by induction of asthma (Fig. 5A and B). Wright-Giemsa staining confirmed that the cells in the G1G2-R3 fraction of BALF, both before and after OVA challenge, were mostly (more than 80\%) eosinophils (data not shown). Taken together, these results show that fully differentiated eosinophils (G1G2-R3 fraction) markedly increase in number and migrate into the lungs in response to allergen challenge. Furthermore, the data suggest that G1Red:G2-GFP mice will be a useful tool in investigating the pathophysiology of allergic disease. 

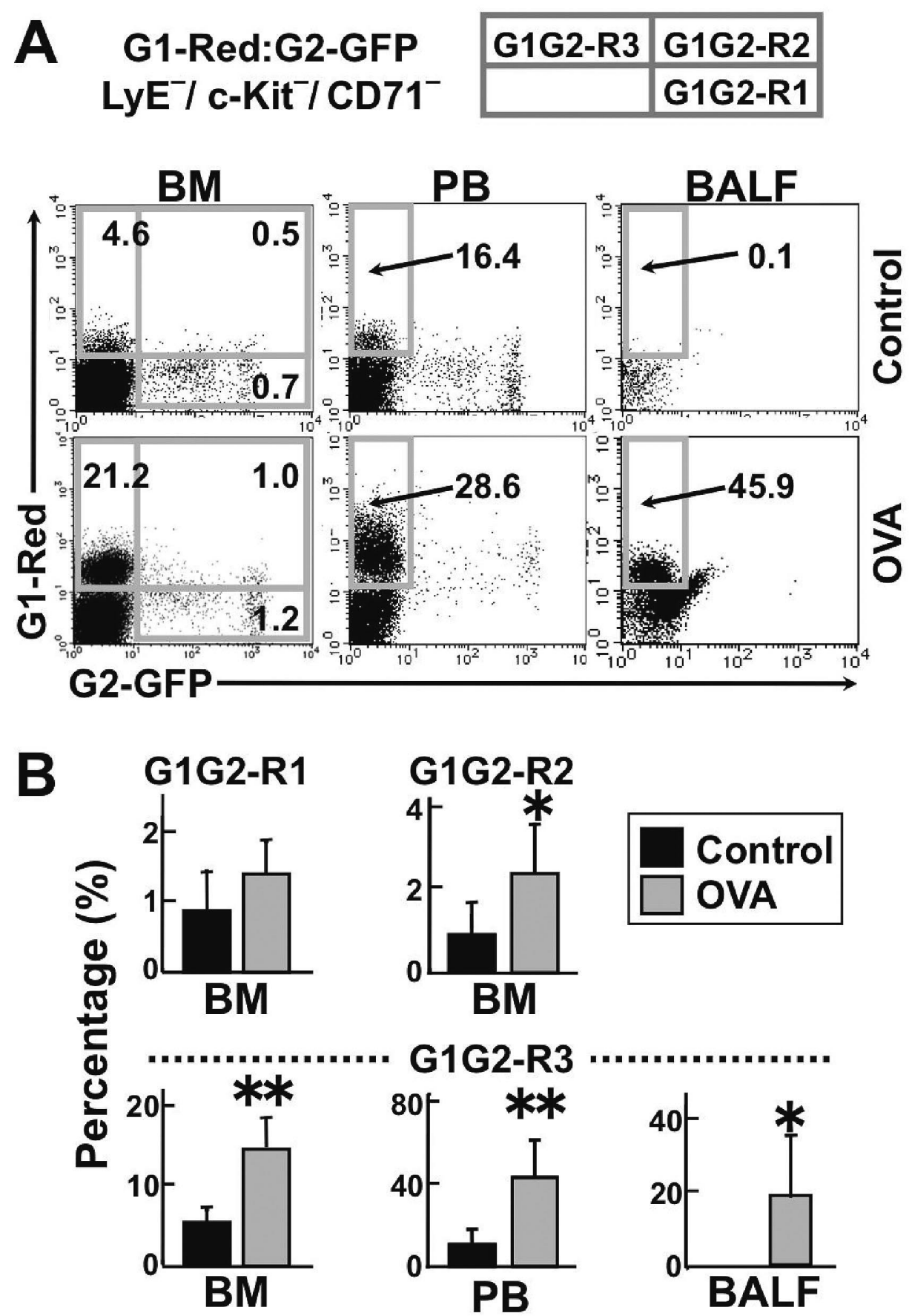

Fig. 5. Allergen challenge induces changes in the eosinophilic cell fractions defined by Gata1-and Gata2- reporter expression.

(A) Flow cytometry for DsRed2 (G1-Red) and GFP (G2-GFP) expression of LyE ${ }^{-} / \mathrm{c}^{-\mathrm{Kit}^{-}} / \mathrm{CD}^{-} 1^{-}$hematopoietic mononuclear cells from bone marrow (BM), peripheral blood (PB) and bronchoalveolar lavage fluid (BALF) of G1-Red:G2-GFP mice before (Control; top row) or after (bottom row) OVA-induced atopic asthma condition. The percentage of cells in each quadrangle is shown. (B) The changes in cell populations are represented by bar graphs with mean \pm S.D. from 3 or more independent experiments (**, $P<0.01 ; *, P<0.05$ compared with the control).

\section{Discussion}

In this study, we established a flow cytometry-based system for eosinophil isolation using Gatal-HRD reporter transgenic mouse lines. Both G1-GFP and G1-Red fluores- cence in the $\mathrm{LyE}^{-} / \mathrm{c}-\mathrm{Kit}^{-} / \mathrm{CD} 71^{-}$fraction efficiently enriched eosinophils in the bone marrow and BALF.

GATA1 expression is restricted to hematopoietic cells and Sertoli cells in the testis (Yamamoto et al. 1990; Ito et al. 1993; Yomogida et al. 1994; Ferreira et al. 2005; Shimizu 
et al. 2008). Gatal-HRD drives expression of GATA1 in erythrocytes/megakaryocyte, basophil, mast cell, and eosinophil cell lineages (Onodera et al. 1997; Suzuki et al. 2003). To achieve efficient fractionation of eosinophils in the bone marrow cell fraction expressing the Gatal-HRD transgene, lymphoid cells (positive for CD4, CD8 or B220), erythroid cells (positive for Ter119 and/or CD71) and c-Kit ${ }^{+}$cells (including hematopoietic progenitors, mast cells and basophils) were eliminated by negative selection with the appropriate antibodies. Megakaryocytes were scarcely detected in the flow cytometry of bone marrow preparations in this study, probably due to their bulky and adhesive cytoplasm. Thus, in vivo eosinophils were effectively collected as G1$\mathrm{GFP}^{+}$or $\mathrm{G} 1-\mathrm{Red}^{+}$cells in the $\mathrm{LyE}^{-} / \mathrm{c}-\mathrm{Kit}^{-} / \mathrm{CD} 71^{-}$fraction from hematopoietic cells in the bone marrow of mice under normal physiological conditions.

We propose that our method of using Gatal-HRD derived fluorescence will be useful in detection and isolation of tissue-infiltrating eosinophils. Eosinophils are easily detected by morphological examination of smear samples from bone marrow and peripheral blood; nevertheless it is not easy to estimate the extent of eosinophil infiltration in inflamed lungs (Foster et al. 1996; Kopf et al. 1996; Shen et al. 2003; Ishizaki et al. 2006). Preparation of mononuclear cell suspensions of the lung is an established technique (Stevens et al. 2007) and several methods to analyze eosinophils in these parenchymal cell suspensions have been reported (Hansel et al. 1991; Du et al. 2002; Iwasaki et al. 2005; Ishizaki et al. 2006; Stevens et al. 2007; Fukushima et al. 2009; Mori et al. 2009; Shen et al. 2009). In previous approaches, eosinophils were fractionated according to specific gravity (Gärtner 1980) or their reactivity to specific antibodies against surface marker antigens with/without forward/side scatter gating (Hansel et al. 1991; Du et al. 2002; Ishizaki et al. 2006; Rothenberg and Hogan 2006). In contrast, we used monoclonal antibodies only for negative selection. Thus, our system minimizes the possibility of cross-reaction of adopted antibodies with hematopoietic or non-hematopoietic cells and of aberrant signal-transductions from antigen-antibody reactions.

As mentioned above, fluorescent proteins expressed by the Gatal-HRD transgenes efficiently labeled mature eosinophils in the $\mathrm{LyE}^{-} / \mathrm{c}-\mathrm{Kit}^{-} / \mathrm{CD} 71^{-}$fraction, while eosinophil progenitors (EoPs) harboring a colony-forming potential were Gatal-HRD reporter-negative in the $\mathrm{LyE}^{-} / \mathrm{c}-\mathrm{Kit}^{+} /$ CD $71^{-}$fraction of bone marrow hematopoietic cells. Consistent with this finding, it has been reported that EoPs are included in c-Kit ${ }^{+}$fraction (Iwasaki et al. 2005: Arinobu et al. 2009; Mori et al. 2009), and that Gatal gene expression in EoP is low compared with other Gatal-expressing cells, including progenitors for basophils, mast cells, megakaryocytes or erythroid cells (Iwasaki et al. 2006). Since Gatal-HRD is not active in the early progenitor stage of erythroid lineage cells (Suzuki et al. 2003), this $8 \mathrm{~kb}$ of the gene regulatory domain may also not be sufficient for regulation of the Gatal gene expression in EoP.
Time-lapse observation of eosinophils during colony formation showed simultaneous fluorescent emission of G1Red and G2-GFP, implying simultaneous expression of the Gatal and Gata2 genes in growing eosinophils. These data were supported by data from flow cytometry analysis of G1Red:G2-GFP mice, which distinguished G1-Red ${ }^{+} / \mathrm{G} 2-\mathrm{GFP}^{+}$ cells (G1G2-R2 fraction in Fig. 3A) in $\mathrm{LyE}^{-} / \mathrm{c}-\mathrm{Kit}^{-} / \mathrm{CD} 71^{-}$ bone marrow cells. In addition, several reports have demonstrated simultaneous expression of the Gatal and Gata2 genes in EoP fractionated with an anti-IL-5R $\alpha$ antibody from mouse bone marrow (Iwasaki et al. 2005, 2006; Mori et al. 2009) or in eosinophils obtained by culturing progenitor cells (Qiu et al. 2009). However, the major eosinophilic fraction in G1-Red:G2-GFP mouse bone marrow is the G1$\mathrm{Red}^{+} / \mathrm{G} 2-\mathrm{GFP}^{-}$(G1G2-R3) fraction, in which the Gata2 mRNA expression level is very low or undetectable by quantitative RT-PCR analysis. We thus suggest that the Gata2 gene is transiently expressed during growth of eosinophils, and that expression is diminished in cells in the G1G2-R3 fraction, which are morphologically characteristic of mature eosinophils.

During hematopoietic development, GATA2 expression is first identified in hematopoietic stem cells and persists in multi-potential progenitors (Minegishi et al. 1998; Iwasaki et al. 2005; Suzuki et al. 2006). GATA2 up-regulates transcription of the Gatal gene in an early stage of erythroid differentiation (Kobayashi-Osaki et al. 2005) and increased GATA1 expression finally represses Gata2 gene transcription in a later stage of erythroid cells (Grass et al. 2003; Johnson et al. 2007). In eosinophil differentiation, it is plausible to speculate that Gata2 gene expression is diminished by GATA1 in a similar way with erythroid cells. Although FOG-1 is essential for repression of the Gata2 gene expression by GATA1 in erythroid lineages (Querfurth et al. 2000; Johnson et al. 2007), Fog 1 mRNA is not expressed in eosinophils. Therefore, we expect that GATA1 might repress the Gata2 gene expression during maturation of eosinophils in a FOG-1-independent fashion.

In this study, we have developed a new method to efficiently fractionate mature eosinophils from bone marrow and BALF by exploiting Gatal-HRD-reporter expression as a useful marker of mature eosinophils. We propose that this method may be useful in pathophysiological studies of eosinophils in hematopoietic and parenchymal tissues.

\section{Acknowledgments}

We would like to thank Drs. Takako Nakano, Masatsugu Ema and Satoru Takahashi (University of Tsukuba) for advice on mouse experiments, and Ms. Masako Yamagishi, Ms. Naomi Kaneko and Mr. Mitsuru Okano (University of Tsukuba) for technical assistance. We would also like to thank Ms. Flaminia Miyamasu (University of Tsukuba) for grammatical review and advice. This study was supported in part by grants-in-aid for Exploratory Research from the Japan Society for the Promotion of Science (JSPS), and for Exploratory Research and Technology (ERATO) from the Japan Science and Technology Agency (JST) (MY). NS is a JSPS fellow. 


\section{References}

Arinobu, Y., Iwasaki, H. \& Akashi, K. (2009) Origin of basophils and mast cells. Allergol. Int., 58, 21-28.

Caldenhoven, E., van Dijk, T.B., Tijmensen, A., Raaijmakers, J.A., Lammers, J.W., Koenderman, L. \& de Groot, R.P. (1998) Differential activation of functionally distinct STAT5 proteins by IL-5 and GM-CSF during eosinophil and neutrophil differentiation from human CD34+ hematopoietic stem cells. Stem Cells, 16, 397-403.

Chang, A.N., Cantor, A.B., Fujiwara, Y., Lodish, M.B., Droho, S., Crispino, J.D. \& Orkin, S.H. (2002) GATA-factor dependence of the multitype zinc-finger protein FOG-1 for its essential role in megakaryopoiesis. Proc. Natl. Acad. Sci. USA, 99, $9237-$ 9242.

Clutterbuck, E.J., Hirst, E.M. \& Sanderson, C.J. (1989) Human interleukin-5 (IL-5) regulates the production of eosinophils in human bone marrow cultures: comparison and interaction with IL-1, IL-3, IL-6, and GMCSF. Blood, 73, 1504-1512.

Clutterbuck, E.J. \& Sanderson, C.J. (1988) Human eosinophil hematopoiesis studied in vitro by means of murine eosinophil differentiation factor (IL5): production of functionally active eosinophils from normal human bone marrow. Blood, 71, 646-651.

Du, J., Stankiewicz, M.J., Liu, Y., Xi, Q., Schmitz, J.E., LekstromHimes, J.A. \& Ackerman, S.J. (2002) Novel combinatorial interactions of GATA-1, PU.1, and C/EBPepsilon isoforms regulate transcription of the gene encoding eosinophil granule major basic protein. J. Biol. Chem., 277, 43481-43494.

Dyer, K.D., Moser, J.M., Czapiga, M., Siegel, S.J., Percopo, C.M. \& Rosenberg, H.F. (2008) Functionally competent eosinophils differentiated ex vivo in high purity from normal mouse bone marrow. J. Immunol., 181, 4004-4009.

Ferreira, R., Ohneda, K., Yamamoto, M. \& Philipsen, S. (2005) GATA1 function, a paradigm for transcription factors in hematopoiesis. Mol. Cell. Biol, 25, 1215-1227.

Foster, P.S., Hogan, S.P., Ramsay, A.J., Matthaei, K.I. \& Young, I.G. (1996) Interleukin 5 deficiency abolishes eosinophilia, airways hyperreactivity, and lung damage in a mouse asthma model. J. Exp. Med., 183, 195-201.

Fujiwara, Y., Browne, C.P., Cunniff, K., Goff, S.C. \& Orkin, S.H. (1996) Arrested development of embryonic red cell precursors in mouse embryos lacking transcription factor GATA-1. Proc. Natl. Acad. Sci. USA, 93, 12355-12358.

Fukushima, K., Matsumura, I., Ezoe, S., Tokunaga, M., Yasumi, M., Satoh, Y., Shibayama, H., Tanaka, H., Iwama, A. \& Kanakura, Y. (2009) FIP1L1-PDGFRalpha imposes eosinophil lineage commitment on hematopoietic stem/progenitor cells. J. Biol. Chem., 284, 7719-7732.

Gärtner, I. (1980) Separation of human eosinophils in density gradients of polyvinylpyrrolidone-coated silica gel (Percoll). Immunology, 40, 133-136.

Gounni, A.S., Gregory, B., Nutku, E., Aris, F., Latifa, K., Minshall, E., North, J., Tavernier, J., Levit, R., Nicolaides, N., Robinson, D. \& Hamid, Q. (2000) Interleukin-9 enhances interleukin-5 receptor expression, differentiation, and survival of human eosinophils. Blood, 96, 2163-2171.

Grass, J.A., Boyer, M.E., Pal, S., Wu, J., Weiss, M.J. \& Bresnick, E.H. (2003) GATA-1-dependent transcriptional repression of GATA-2 via disruption of positive autoregulation and domainwide chromatin remodeling. Proc. Natl. Acad. Sci. USA, 100, 8811-8816.

Gutiérrez, L., Nikolic, T., van Dijk, T.B., Hammad, H., Vos, N., Willart, M., Grosveld, F., Philipsen, S. \& Lambrecht, B.N. (2007) Gata1 regulates dendritic-cell development and survival. Blood, 110, 1933-1941.

Guyot, B., Valverde-Garduno, V., Porcher, C. \& Vyas, P. (2004) Deletion of the major GATA1 enhancer HS 1 does not affect eosinophil GATA1 expression and eosinophil differentiation.
Blood, 104, 89-91.

Hansel, T.T., De Vries, I.J., Iff, T., Rihs, S., Wandzilak, M., Betz, S., Blaser, K. \& Walker, C. (1991) An improved immunomagnetic procedure for the isolation of highly purified human blood eosinophils. J. Immunol. Methods, 145, 105-110.

Harigae, H., Takahashi, S., Suwabe, N., Ohtsu, H., Gu, L., Yang, Z., Tsai, F.Y., Kitamura, Y., Engel, J.D. \& Yamamoto, M. (1998) Differential roles of GATA-1 and GATA-2 in growth and differentiation of mast cells. Genes Cells, 3, 39-50.

Hirasawa, R., Shimizu, R., Takahashi, S., Osawa, M., Takayanagi, S., Kato, Y., Onodera, M., Minegishi, N., Yamamoto, M., Fukao, K., Taniguchi, H., Nakauchi, H. \& Iwama, A. (2002) Essential and instructive roles of GATA factors in eosinophil development. J. Exp. Med., 195, 1379-1386.

Humbles, A.A., Lloyd, C.M., McMillan, S.J., Friend, D.S., Xanthou, G., McKenna, E.E., Ghiran, S., Gerard, N.P., Yu, C., Orkin, S.H. \& Gerard, C. (2004) A critical role for eosinophils in allergic airways remodeling. Science, 305, 1776-1779.

Ishizaki, H., Togawa, A., Tanaka-Okamoto, M., Hori, K., Nishimura, M., Hamaguchi, A., Imai, T., Takai, Y. \& Miyoshi, J. (2006) Defective chemokine-directed lymphocyte migration and development in the absence of Rho guanosine diphosphatedissociation inhibitors alpha and beta. J. Immunol., 177, $8512-8521$

Ito, E., Toki, T., Ishihara, H., Ohtani, H., Gu, L., Yokoyama, M., Engel, J.D. \& Yamamoto, M. (1993) Erythroid transcription factor GATA-1 is abundantly transcribed in mouse testis. Nature, 362, 466-468.

Iwasaki, H., Mizuno, S., Arinobu, Y., Ozawa, H., Mori, Y., Shigematsu, H., Takatsu, K., Tenen, D.G. \& Akashi, K. (2006) The order of expression of transcription factors directs hierarchical specification of hematopoietic lineages. Genes Dev., 20, 3010-3021.

Iwasaki, H., Mizuno, S., Mayfield, R., Shigematsu, H., Arinobu, Y., Seed, B., Gurish, M.F., Takatsu, K. \& Akashi, K. (2005) Identification of eosinophil lineage-committed progenitors in the murine bone marrow. J. Exp. Med., 201, 1891-1897.

Johnson, K.D., Boyer, M.E., Kang, J.A., Wickrema, A., Cantor, A.B \& Bresnick, E.H. (2007) Friend of GATA-1-independent transcriptional repression: a novel mode of GATA-1 function. Blood, 109, 5230-5233.

Kobayashi-Osaki, M., Ohneda, O., Suzuki, N., Minegishi, N., Yokomizo, T., Takahashi, S., Lim, K.C., Engel, J.D. \& Yamamoto, M. (2005) GATA motifs regulate early hematopoietic lineage-specific expression of the Gata2 gene. Mol. Cell. Biol., 25, 7005-7020.

Kopf, M., Brombacher, F., Hodgkin, P.D., Ramsay, A.J., Milbourne, E.A., Dai, W.J., Ovington, K.S., Behm, C.A., Köhler, G., Young, I.G. \& Matthaei, K.I. (1996) IL-5-deficient mice have a developmental defect in CD5+ B-1 cells and lack eosinophilia but have normal antibody and cytotoxic $\mathrm{T}$ cell responses. Immunity, 4, 15-24.

Lee, J.J., Dimina, D., Macias, M.P., Ochkur, S.I., McGarry, M.P., O’Neill, K.R., Protheroe, C., Pero, R., Nguyen, T., Cormier, S.A., Lenkiewicz, E., Colbert, D., Rinaldi, L., Ackerman, S.J., Irvin, C.G. \& Lee, N.A. (2004) Defining a link with asthma in mice congenitally deficient in eosinophils. Science, $\mathbf{3 0 5}$, 1773-1776.

McNagny, K. \& Graf, T. (2002) Making eosinophils through subtle shifts in transcription factor expression. J. Exp. Med., 195, F43-F47.

Minegishi, N., Ohta, J., Suwabe, N., Nakauchi, H., Ishihara, H., Hayashi, N. \& Yamamoto, M. (1998) Alternative promoters regulate transcription of the mouse GATA-2 gene. J. Biol. Chem., 273, 3625-3634.

Minegishi, N., Suzuki, N., Yokomizo, T., Pan, X., Fujimoto, T., Takahashi, S., Hara, T., Miyajima, A., Nishikawa, S. \& Yamamoto, M. (2003) Expression and domain-specific function of GATA-2 during differentiation of the hematopoietic 
precursor cells in midgestation mouse embryos. Blood, 102, 896-905.

Mori, Y., Iwasaki, H., Kohno, K., Yoshimoto, G., Kikushige, Y., Okeda, A., Uike, N., Niiro, H., Takenaka, K., Nagafuji, K., Miyamoto, T., Harada, M., Takatsu, K. \& Akashi, K. (2009) Identification of the human eosinophil lineage-committed progenitor: revision of phenotypic definition of the human common myeloid progenitor. J. Exp. Med., 206, 183-193.

Munoz, N.M. \& Leff, A.R. (2006) Highly purified selective isolation of eosinophils from human peripheral blood by negative immunomagnetic selection. Nat. Protoc., 1, 2613-2620.

Muntean, A.G., Pang, L., Poncz, M., Dowdy, S.F., Blobel, G.A. \& Crispino, J.D. (2007) Cyclin D-Cdk4 is regulated by GATA-1 and required for megakaryocyte growth and polyploidization. Blood, 109, 5199-5207.

Onodera, K., Takahashi, S., Nishimura, S., Ohta, J., Motohashi, H., Yomogida, K., Hayashi, N., Engel, J.D. \& Yamamoto, M. (1997) GATA-1 transcription is controlled by distinct regulatory mechanisms during primitive and definitive erythropoiesis. Proc. Natl. Acad. Sci. USA, 94, 4487-4492.

Qiu, Z., Dyer, K.D., Xie, Z., Radinger, M. \& Rosenberg, H.F. (2009) GATA Transcription factors regulate the expression of the human eosinophil-derived neurotoxin (RNase 2) gene. J. Biol. Chem., 284, 13099-13109.

Querfurth, E., Schuster, M., Kulessa, H., Crispino, J.D., Doderlein, G., Orkin, S.H., Graf, T. \& Nerlov, C. (2000) Antagonism between $\mathrm{C} / \mathrm{EBPbeta}$ and FOG in eosinophil lineage commitment of multipotent hematopoietic progenitors. Genes Dev., 14, 2515-2525.

Rothenberg, M.E. \& Hogan, S.P. (2006) The eosinophil. Annu. Rev. Immunol., 24, 147-174.

Sakai, K., Yokoyama, A., Kohno, N. \& Hiwada, K. (1999) Effect of different sensitizing doses of antigen in a murine model of atopic asthma. Clin. Exp. Immunol., 118, 9-15.

Shen, H.H., Ochkur, S.I., McGarry, M.P., Crosby, J.R., Hines, E.M., Borchers, M.T., Wang, H., Biechelle, T.L., O’Neill, K.R., Ansay, T.L., Colbert, D.C., Cormier, S.A., Justice, J.P., Lee, N.A. \& Lee, J.J. (2003) A causative relationship exists between eosinophils and the development of allergic pulmonary pathologies in the mouse. J. Immunol., 170, 3296-3305.

Shen, Z.J., Esnault, S., Schinzel, A., Borner, C. \& Malter, J.S. (2009) The peptidyl-prolyl isomerase Pin 1 facilitates cytokineinduced survival of eosinophils by suppressing Bax activation. Nat. Immunol., 10, 257-265.

Shimizu, R., Engel, J.D. \& Yamamoto, M. (2008) GATA1-related leukaemias. Nat. Rev. Cancer, 8, 279-287.

Stevens, W.W., Kim, T.S., Pujanauski, L.M., Hao, X. \& Braciale, T.J. (2007) Detection and quantitiation of eosinophils in the murine respiratory tract by flow cytometry. J. Immunol. Methods, 327, 63-74.

Suzuki, N., Ohneda, O., Minegishi, N., Nishikawa, M., Ohta, T., Takahashi, S., Engel, J.D. \& Yamamoto, M. (2006) Combinatorial Gata2 and Sca1 expression defines hematopoietic stem cells in the bone marrow niche. Proc. Natl. Acad. Sci. USA, 103, 2202-2207.

Suzuki, N., Suwabe, N., Ohneda, O., Obara, N., Imagawa, S., Pan,
X., Motohashi, H. \& Yamamoto, M. (2003) Identification and characterization of 2 types of erythroid progenitors that express GATA-1 at distinct levels. Blood, 102, 3575-3583.

Takahashi, S., Komeno, T., Suwabe, N., Yoh, K., Nakajima, O., Nishimura, S., Kuroha, T., Nagasawa, T. \& Yamamoto, M. (1998) Role of GATA-1 in proliferation and differentiation of definitive erythroid and megakaryocytic cells in vivo. Blood, 92, 434-442.

Takahashi, S., Onodera, K., Motohashi, H., Suwabe, N., Hayashi, N., Yanai, N., Nabesima, Y. \& Yamamoto, M. (1997) Arrest in primitive erythroid cell development caused by promoter-specific disruption of the GATA-1 gene. J. Biol. Chem., 272, 12611-12615.

Takemoto, C.M., Lee, Y.N., Jegga, A.G., Zablocki, D., Brandal, S., Shahlaee, A., Huang, S., Ye, Y., Gowrisankar, S., Huynh, J. \& McDevitt, M.A. (2008) Mast cell transcriptional networks. Blood Cells Mol. Dis., 41, 82-90.

Tsai, F.Y., Keller, G., Kuo, F.C., Weiss, M., Chen, J., Rosenblatt, M., Alt, F.W. \& Orkin, S.H. (1994) An early haematopoietic defect in mice lacking the transcription factor GATA-2. Nature, 371, 221-226.

Weiss, M.J. \& Orkin, S.H. (1995) GATA transcription factors: key regulators of hematopoiesis. Exp. Hematol., 23, 99-107.

Yamaguchi, Y., Ackerman, S.J., Minegishi, N., Takiguchi, M., Yamamoto, M. \& Suda, T. (1998) Mechanisms of transcription in eosinophils: GATA-1, but not GATA-2, transactivates the promoter of the eosinophil granule major basic protein gene. Blood, 91, 3447-3458.

Yamaguchi, Y., Nishio, H., Kishi, K., Ackerman, S.J. \& Suda, T. (1999) C/EBPbeta and GATA-1 synergistically regulate activity of the eosinophil granule major basic protein promoter: implication for C/EBPbeta activity in eosinophil gene expression. Blood, 94, 1429-1439.

Yamamoto, M., Ko, L.J., Leonard, M.W., Beug, H., Orkin, S.H. \& Engel, J.D. (1990) Activity and tissue-specific expression of the transcription factor NF-E1 multigene family. Genes Dev., $\mathbf{4}$, $1650-1662$.

Yang, D., Suzuki, S., Hao, L.J., Fujii, Y., Yamauchi, A., Yamamoto, M., Nakamura, M. \& Kumatori, A. (2000) Eosinophil-specific regulation of gp91(phox) gene expression by transcription factors GATA-1 and GATA-2. J. Biol. Chem., 275, 9425-9432.

Yomogida, K., Ohtani, H., Harigae, H., Ito, E., Nishimune, Y., Engel, J.D. \& Yamamoto, M. (1994) Developmental stageand spermatogenic cycle-specific expression of transcription factor GATA-1 in mouse Sertoli cells. Development, 120, $1759-1766$.

Yu, C., Cantor, A.B., Yang, H., Browne, C., Wells, R.A., Fujiwara, Y. \& Orkin, S.H. (2002) Targeted deletion of a high-affinity GATA-binding site in the GATA-1 promoter leads to selective loss of the eosinophil lineage in vivo. J. Exp. Med., 195, $1387-1395$.

Zon, L.I., Yamaguchi, Y., Yee, K., Albee, E.A., Kimura, A., Bennett, J.C., Orkin, S.H. \& Ackerman, S.J. (1993) Expression of mRNA for the GATA-binding proteins in human eosinophils and basophils: potential role in gene transcription. Blood, 81, 3234-3241. 